\title{
Overflow Analysis of Unmanned Aircraft Systems
}

\author{
Paul M. Stremel ${ }^{1}$ \\ Science and Technology Corporation, NASA Research Park, CA, 94035, USA \\ and \\ Jasim U. Ahmad ${ }^{2}$ \\ NASA Ames Research Center, Moffett Field, CA, 94035, USA
}

\begin{abstract}
With the increasing presence of unmanned aircraft systems (UAS), or drones, in the national airspace, the management for access and operation of these vehicles is required. NASA's management approach is being developed under the unmanned aircraft system traffic management (UTM) program. To determine the aerodynamic characteristics of drones, wind tunnel experiments and computation fluid dynamic (CFD) analysis have been conducted. These experiments and analyses are undertaken to understand the flight capabilities of these vehicles in variable head and cross wind conditions. The results of these investigations will provide metrics for the safe operation of these vehicles in and around civil populations and in urban settings. The focus of this paper is to model a drone installed in a wind tunnel for varying pitch attitudes and rotor rpm settings. Specifically, the IRIS drone is modeled in the NASA-Ames $7 \times 10 \mathrm{ft}$ wind tunnel. The tunnel mounting hardware and the tunnel enclosure are modeled along with the IRIS drone geometry. The rotors of the drone are modeled using two methodologies: a rotor disk model and full rotating rotors with moving grids. The results of the analysis are compared with available experimental data to validate the computational approach.
\end{abstract}

$\begin{array}{ll} & \\ \mathrm{Cp} & =\text { Coefficient of pressure } \\ \mathrm{lbf} & =\text { Pound force } \\ \mathrm{FM} & =\text { Figure of merit } \\ \mathrm{FX}, \mathrm{FY}, \mathrm{FZ} & =\text { Dimensional forces in X, Y, and Z coordinates, lbf } \\ \mathrm{rpm} & =\text { Revolutions per minute } \\ \mathrm{X}, \mathrm{Y}, \mathrm{Z} & =\text { Grid system coordinates } \\ \alpha & =\text { angle of attack } \\ \text { Acronyms } & \\ \text { ARC } & =\text { Ames Research Center } \\ \text { CFD } & =\text { computational fluid dynamics } \\ \text { MUAS } & =\text { Multicopter UAS NASA-Ames 7x10 W/T Test } \\ \text { UAS } & =\text { unmanned aircraft system } \\ \text { UTM } & =\text { unmanned aircraft system traffic management }\end{array}$

\section{Introduction}

$\mathrm{T}$ he introduction of unmanned aircraft systems (UAS), or drones, into the national airspace must be managed to provide a safe operation environment for the vehicles and the public. This vehicle management approach is being addressed under NASA's unmanned airspace system traffic management (UTM) purview. This vehicle

\footnotetext{
${ }^{1}$ Senior Research Scientist, Mail Stop 258-1, AIAA Member.

${ }^{2}$ Aerospace Engineer, Computational Physics Branch, Exploration Technology Directorate, Mail Stop 258-1, AIAA Member.
} 
management is required to address access to the national airspace and an understanding of the flight characteristics of drones in free flight and within urban settings. The aerodynamics characteristics of unmanned drones can be adversely affected by variations in cross wind, obstructions, and variations in onset flow due to wind shadows from structures. To understand the behavior of the flight of drones in variable conditions, experimental and computational analyses have been conducted. These analyses help to define the limitations of drones in adverse and variable flow conditions. These limitations will help provide a basis for the safe operational envelope of drone flight. The focus of this paper is to provide simulations of a drone installed in a wind tunnel enclosure. These simulations include variations in the tunnel velocity, angle of attack, and rotor rpm. The results of the simulations are compared with available wind tunnel data. The accuracy of the aerodynamic predictions of the drone in the wind tunnel, when compared to existing wind tunnel data, will provide confidence to simulate the vehicle in free flight and within an urban setting. The approach to this study will be presented in the next section.

\section{Technical Approach}

The simulation of a 3DRobotics IRIS drone in the NASA-Ames $7 \times 10 \mathrm{ft}$. wind tunnel was conducted using the CFD solver OVERFLOW [1]. Modeling the drone in the wind tunnel will provide a direct comparison with existing experimental data [2]. The simulations will be conducted for flow conditions reported in Ref. [2] to create direct data comparisons. In this study the rotors are modeled with two different approaches, the first being a rotor disk model and the second is the full unsteady flow with moving rotor grids. The rotor disk model, is an enhanced model of the popularly known actuator disk model widely used to represent a rotor, propeller or turbine. The actuator diskRANS model was first applied to study helicopter rotors [3]. While, the rotor disk model provides a quasi-steady approximation of the rotor to reduce the complexity of the unsteady flow of a rotary wing with a physical simplification. A solid infinitely thin annular zone is substituted for the rotor along the blade path and dynamics effects are modeled and applied to the medium as it flows through the disk. The rotor disk model uses Blade Element Theory for the aerodynamic forces on the blade which is represented by $2 \mathrm{D}$ airfoil sections along the blade. Airfoil tables define the sectional aerodynamic characteristics. These airfoil tables along with the computed flow field are used to define source terms defining the rotor. These source terms are utilized in the governing equations to model the influence of the rotors on the flow. The rotor disk model was implemented in an earlier version of the OVERFLOW code [3]. The full unsteady approach represents rotors as individual blades with moving grids. The moving body simulation is accomplished using OVERLOW-D mode within the OVERFLOW solver. The blades are considered rigid in this study.

OVERFLOW is a state-of-the-art CFD code developed at NASA that solves the time-dependent, Reynoldsaveraged Navier-Stokes (RANS) equations. The code uses overset grids with generalized curvilinear coordinates. The code has many options, such as higher-order differencing of the convective flux derivatives and various turbulence models, including Detached Eddy Simulation (DES). The computational domain extends to the wind tunnel enclosure using Cartesian off-body grids. A description of the grids is presented in the next section.

\section{Computational Grids}

Overset structured grids are used to model the IRIS drone and the wind tunnel geometries. Overset grids are, in general, more difficult to generate but provide excellent grid resolution to simulate viscous boundary layers and separated flow structures surrounding vehicle configurations. This includes the modeling of the interior of the wind tunnel and the grids surrounding the IRIS drone. The orientation of the wind tunnel geometry is depicted in Fig. 1 with the wind tunnel installation shown in Fig. 1a and the computational grids in Fig. 1b. The $\mathrm{X}$ direction is downstream, $\mathrm{Y}$ direction is to the right looking upstream, and $\mathrm{Z}$ is vertical up. The IRIS drone is mounted on a load cell at the end of the sting and is rotated (rolled) 90 degrees to the freestream. This rotation aligns the vertical axis of the drone with the $\mathrm{Y}$ axis. In this orientation, variations in model pitch are created using the wind tunnel turntable rotation. Sideslip is not modeled in the current investigation. The tunnel is modeled as a constant cross section extending upstream and downstream of the model, Fig. 2. Also shown in Fig 2 are the wind tunnel support, sting, and IRIS drone grids, as modeled in the wind tunnel. 


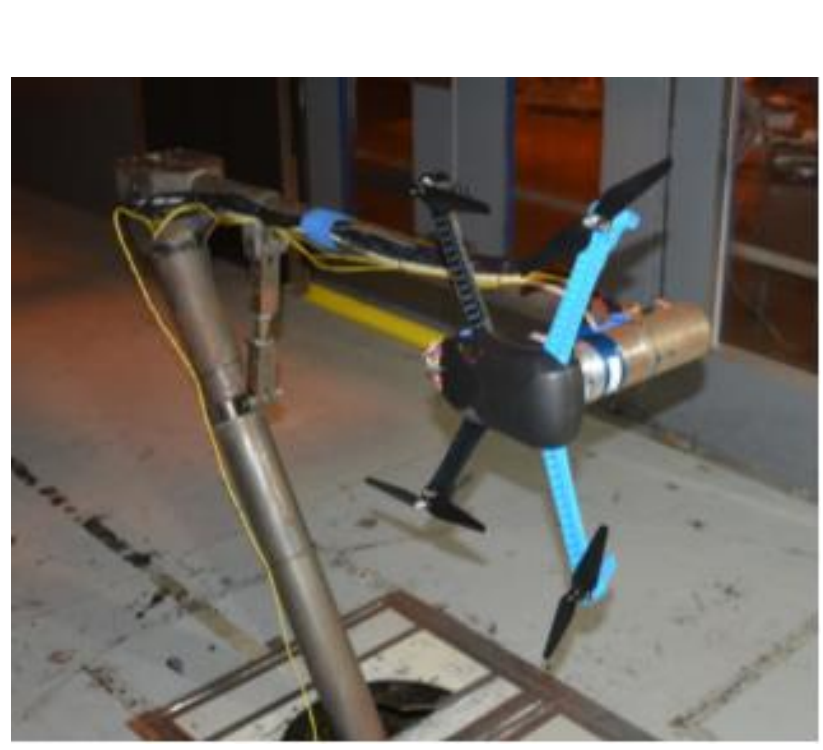

(a)

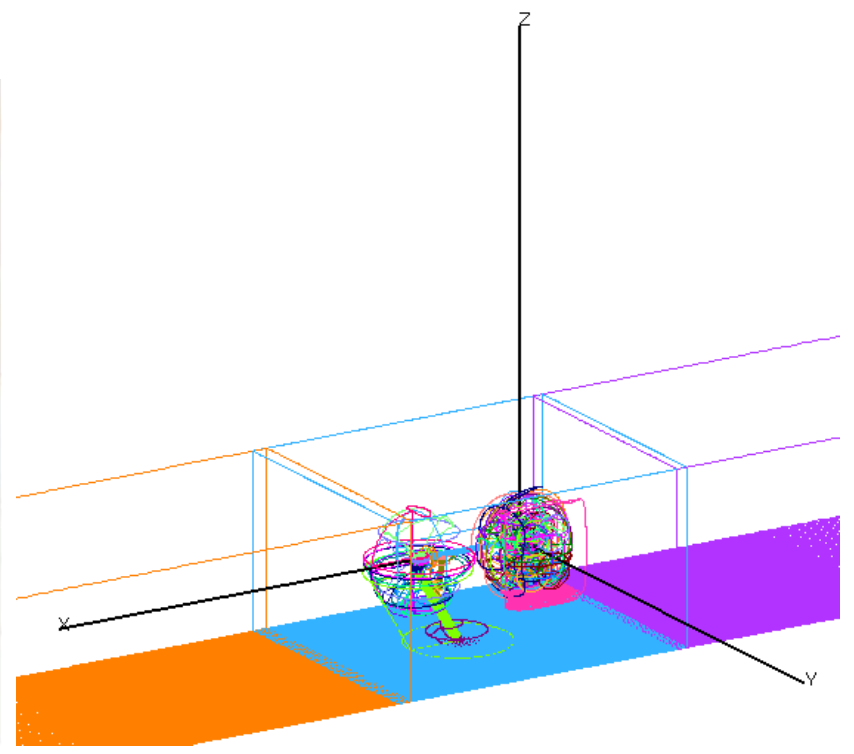

(b)

Figure 1. Overset Grid Orientation, IRIS drone in NASA-Ames 7x10 ft. W/T. (a) Wind tunnel installation, (b) Computational grid. $\mathrm{X}$ downstream, $\mathrm{Y}$ right facing upstream, $\mathrm{Z}$ vertical.

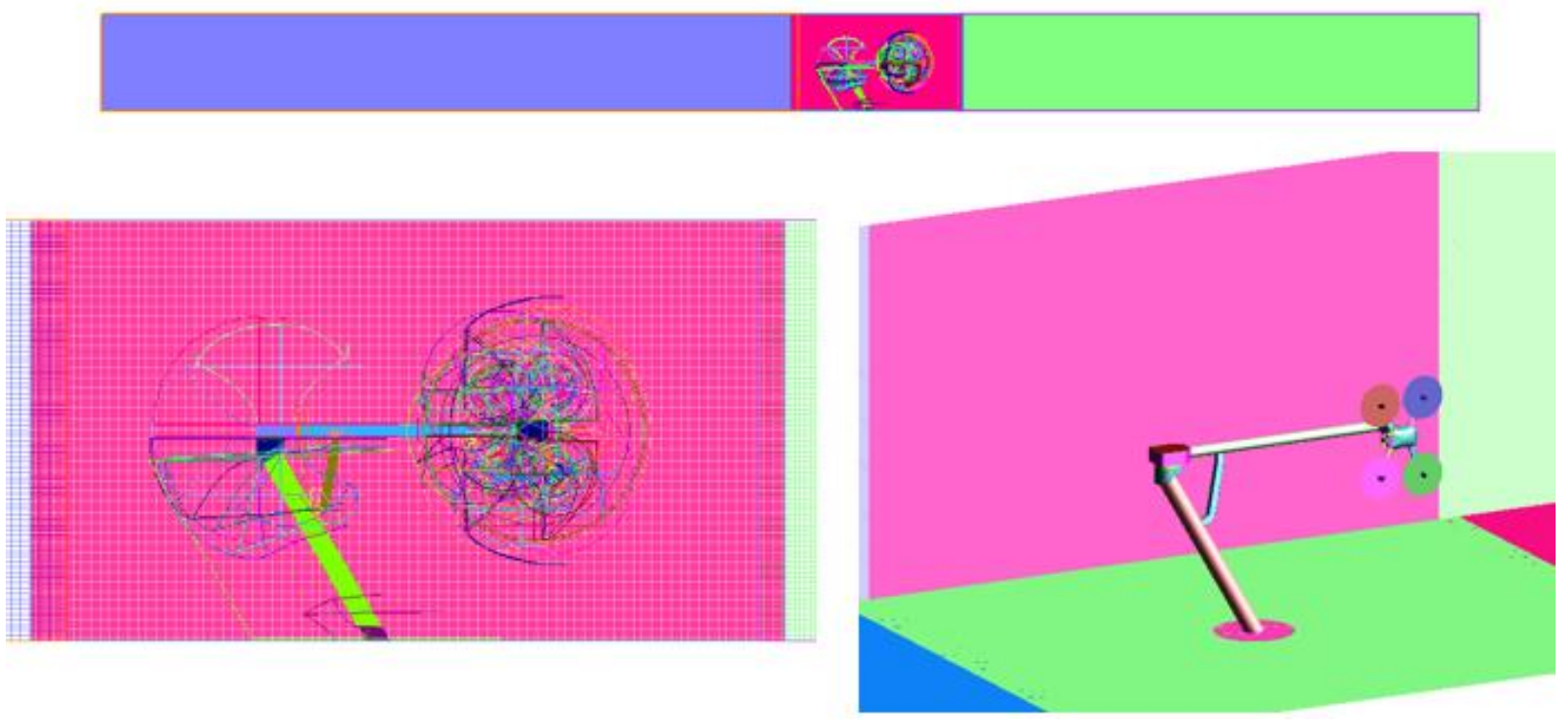

Figure 2. IRIS drone and NASA-Ames $7 \times 10$ ft. wind tunnel grids.

\section{A. Rotor Disk Model Grids}

To model each rotor using the rotor disk model, a disk grid is created at each rotor location. The grid used to model the rotor disk is shown in Fig. 3. The rotor disk grid is refined at the root and tip locations with respect to the radius and above and below the rotor disk in the direction of the rotor axis. This grid refinement better defines the flow at the root and tip locations and into and out of the rotor disk. The rotation sense for each of the four rotors is depicted in the figure. The surface grids for the IRIS drone are also shown in Fig. 3. 


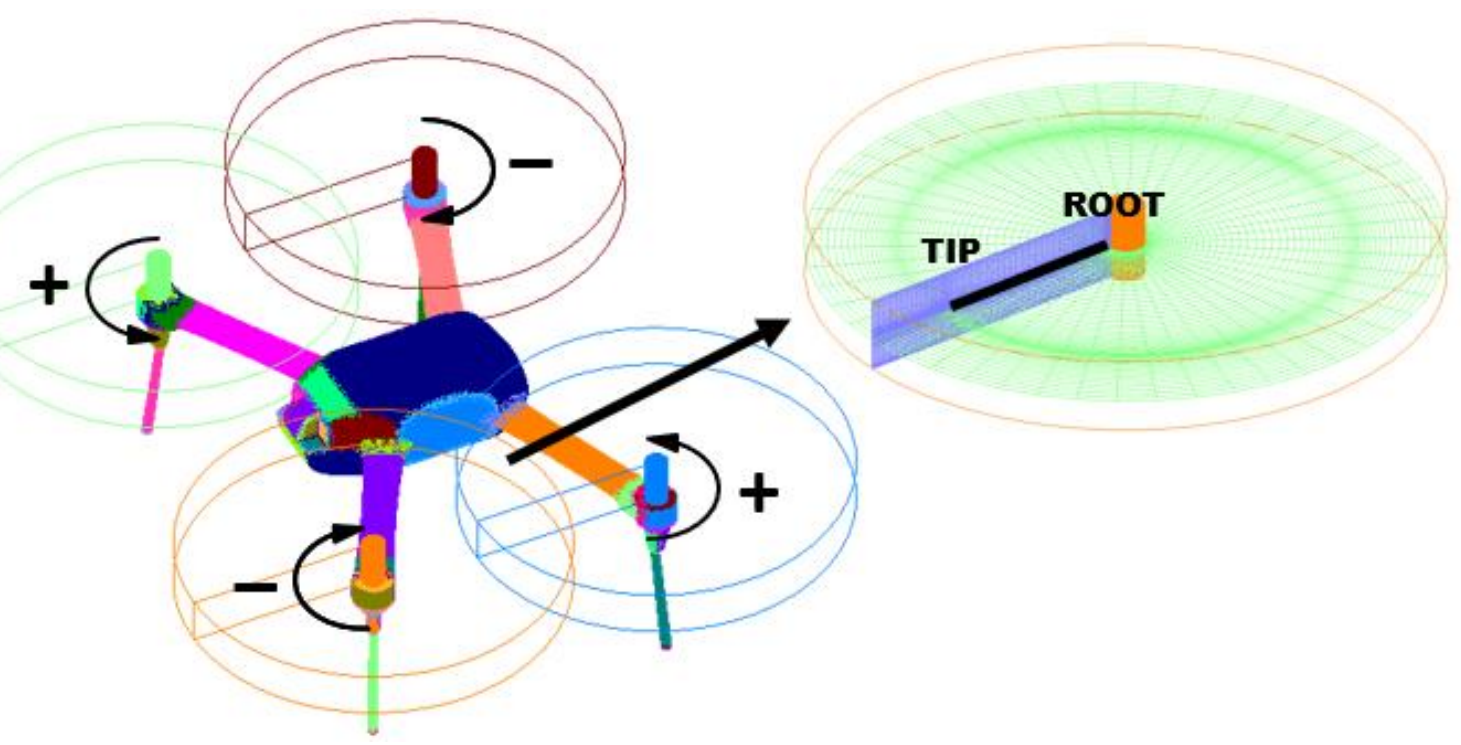

Figure 3. Rotor disk model grids.

\section{B. Individual Blade Grids}

To model each rotor using individual blades, separate grids are created for each blade and hub. Additional grids are created for the blade tip and root geometry, with collar grids joining the blades to the rotor hub. The grids used to model the individual rotor blades and the surface grids for the IRIS drone are shown in Fig 4. The individual blade grids have the same rotation sense as the rotor disk model, Fig. 3.

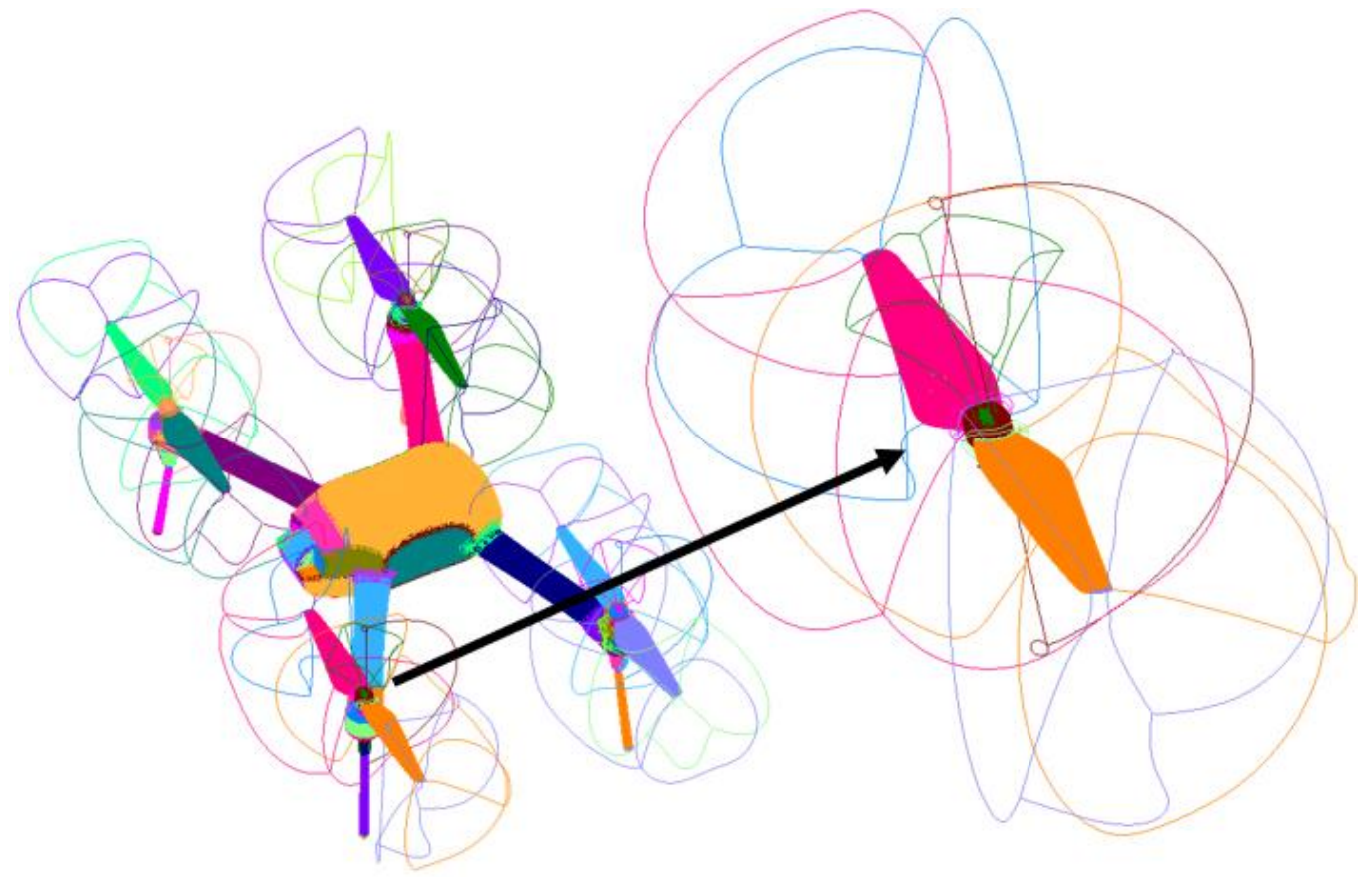

Figure 4. Individual blade grids for full unsteady simulations.

4

American Institute of Aeronautics and Astronautics 


\section{Computational Implementation}

The OVERFLOW solver was used to simulate the IRIS drone in the NASA-Ames wind tunnel. The simulations were designed to model hover and wind tunnel flow conditions for a range of angles of attack and rotor rpm. The tunnel flow was set to Mach 0.0 (hover) and 0.0179. The angle of attack varied from $-40^{\circ}$ to $0^{\circ}$ and the rotor rpm varied from $4000 \mathrm{rpm}$ to $7000 \mathrm{rpm}$. The rotor rpm was held constant for all rotors. All solutions incorporated a Reynolds number based on a reference Mach number of 0.0179. To model angle of attack, the IRIS drone, wind tunnel sting, and support are rotated about the wind tunnel turntable rotation point. To model the hover condition, the IRIS model, wind tunnel sting, and support are rotated to $90^{\circ}$ with respect to the wind tunnel turntable rotation point. For hover, the rotors are thrusting downstream in the tunnel and not across the tunnel width. Model orientation in the wind tunnel for three flow conditions are shown in Fig. 5.

Tunnel Wall

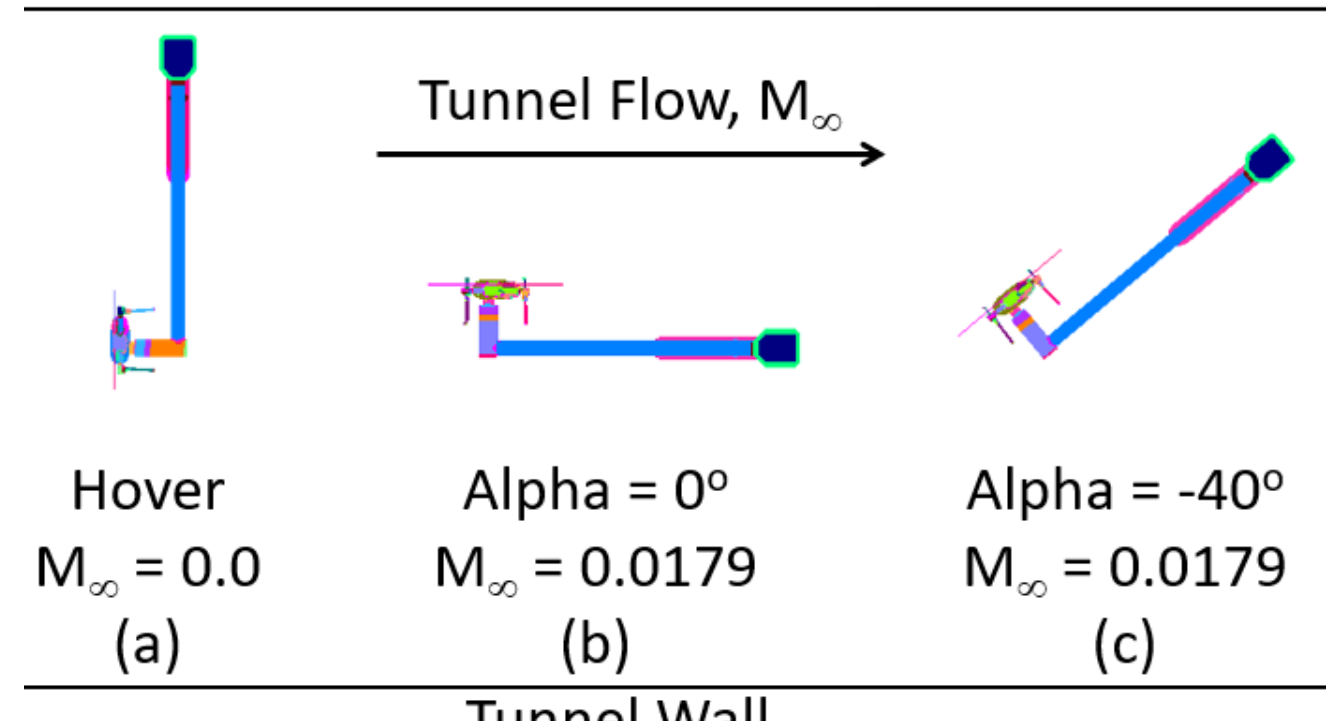

Figure 5. Model orientation in wind tunnel for various flow conditions.

Both solution methodologies, rotor disk model and individual blades, utilized the DCF approach [4] integral to OVERFLOW and the OVERFLOW X-Ray methodology which uses an XML file called Config.xml. 


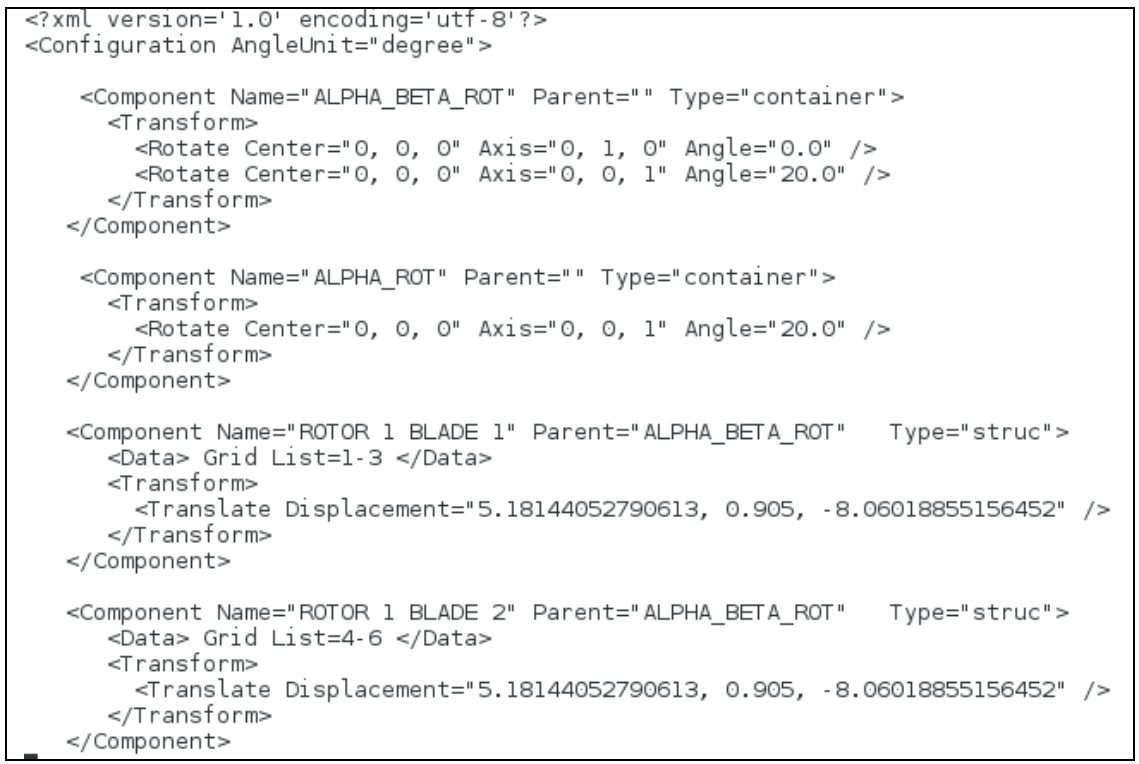

Figure 6. OVERFLOW grid position file, Config.xml.

The Config.xml file, Fig 6, contains the transformation instructions for the IRIS drone grid system. The drone vertical axis is aligned with the $\mathrm{Y}$ axis in the tunnel installation. Two containers are defined in the file to address the separate rotation of specific grids. The first container "ALPHA_BETA_ROT" defines the rotation of the IRIS drone, and the second container "ALPHA_ROT" defines the rotation of the tunnel sting and support. The "ALPHA_BETA_ROT" container first rotates about the $\mathrm{Y}$ axis (Yaw) and then the $\mathrm{Z}$ axis (Pitch). This allows the IRIS drone to include side slip rotation prior to pitch rotation. Side slip is not modeled in this analysis but was measured in the experimental investigation.

\section{A. Rotor Disk Model Simulation Inputs}

In the rotor disk model, the rotor aeromechanic components are controlled by a set of input parameters. These input parameters include physical blade properties (chord and twist) and rotor trim control. The blade geometry, blade chord and thickness were extracted from a CAD model of the IRIS drone rotor blade. These values are shown in Fig. 7. The physical blade properties are specified at 20 radial stations. These properties are used to determine lift and drag from airfoil table data. The lift and drag are then used to compute the source terms used in the governing equations to represent the rotor. In the absence of airfoil table data, the user has the option to specify the lift, drag, and moments using idealized or other simplified aerodynamic models. 
Disk Model Grid
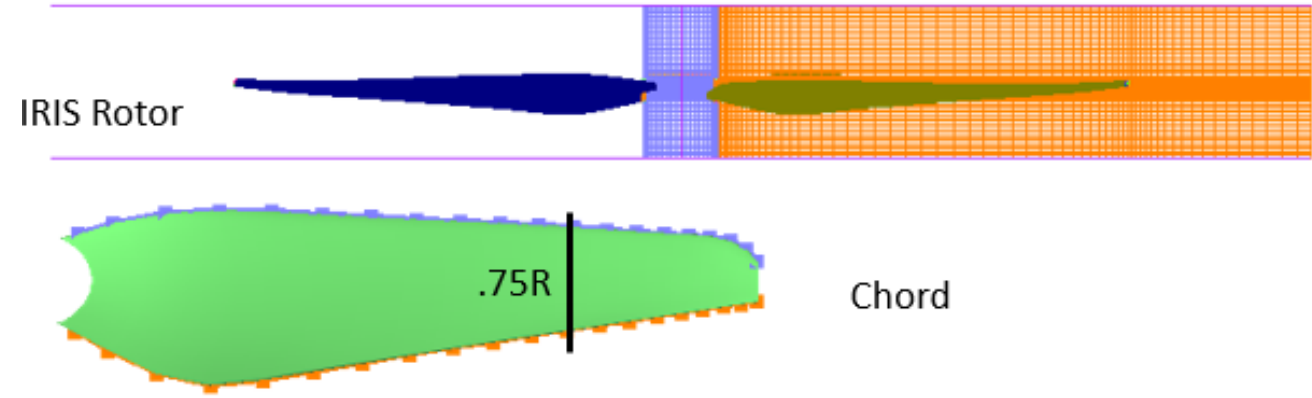

cordr $=0.1398,0.1830,0.2347,0.2566,0.2455,0.2277,0.2112,0.1960,0.1822,0.1697,0.1578$, $0.1468,0.1368,0.1272,0.1188,0.1113,0.1034,0.0927,0.0772,0.0571$,

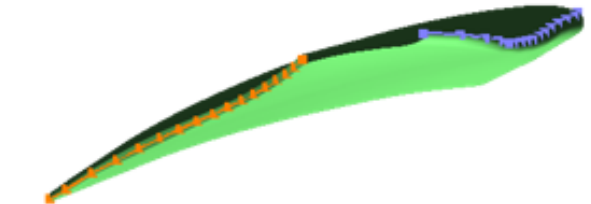

Twist

twstr $=0.377,2.615,5.400,6.352,5.845,4.926,4.202,3.202,2.266,1.477,0.609,0.000,-0.483$, $-1.213,-1.943,-2.675,-3.119,-3.009,-2.283,-1.243$,

\section{Figure 7. IRIS rotor blade distribution of chord and twist}

The twist distribution was modified with respect to the $75 \%$ radial station twist, $13.18^{\circ}$. Then the collective for the rotor disk simulation is set to $13.18^{\circ}$, the twist at the $75 \%$ radial station. The blade thickness was constant at $9.5 \%$ local chord.

The rotor disk model allows the user to define sectional aerodynamic characteristics with theoretical values or from airfoil tables. The theoretical values define sectional aerodynamic characteristics based on theoretical force variations with angle of attack. The airfoil table definitions provide values for the sectional aerodynamic characteristics based on experimental or computational values. Two airfoil table solutions were used in this investigation: the XV15 airfoil tables and the SUI074 tables. The SUI074 airfoil tables were created using sectional airfoil geometries more representative of drone rotor blades.

\section{B. Individual Rotor Blade Simulation Inputs}

The individual blade simulations use the OVERLFOW-D mode to simulate grid motion. For rotor motions, the Scenario.xml file is required. A portion of the Scenario.xml file is shown in Fig 8 and contains the motion instructions for the IRIS drone grid system. This portion of the file defines the motion of the rotor blades and hub for rotor 1 and rotor2. The rotor blades and hubs rotate about the $\mathrm{Y}$ axis at the center of the hub for the respective rotors. Note the opposite rotation for the rotors: " $0,-1,0$ " for rotor 1 and " $0,1,0$ " for rotor2. The Scenario.xml file contains the motion instructions for all the rotor components, some of which are not shown in Fig. 8. 


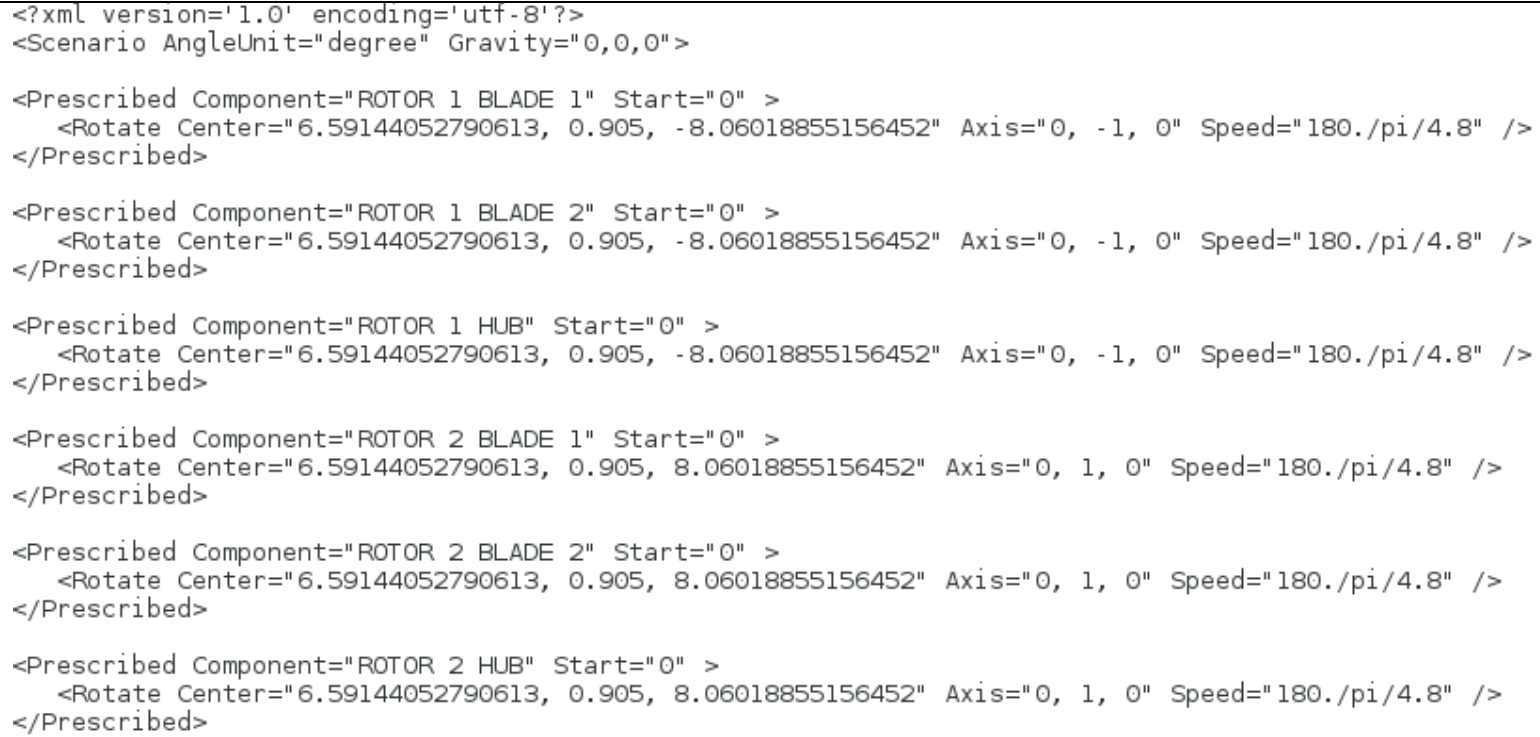

Figure 8. OVERFLOW grid motion file, Scenario.xml

\section{Results}

\section{A. Rotor Disk Model Simulation Results}

OVERFLOW results for the IRIS drone in the NASA-Ames 7x10 ft. wind tunnel at Mach 0.0179 for varying angles of attack are shown in Fig. 9 for the theoretical inputs to the rotor disk model. These results represent the forward flight condition as shown in Fig. 5b, 5c. Shown in Fig. 9 is a comparison of the predicted results using theoretical representations of the rotor blade sectional aerodynamics and the IRIS drone measurements from the MUAS data [2]. The trend in the predicted data is consistently offset from the measured values, and the offset increases with larger angle of attack magnitudes.

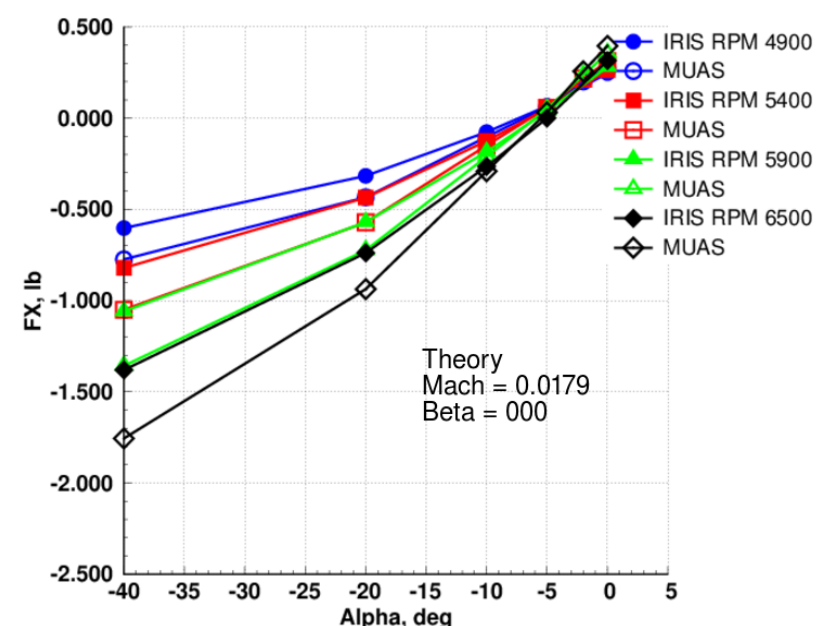

(a)

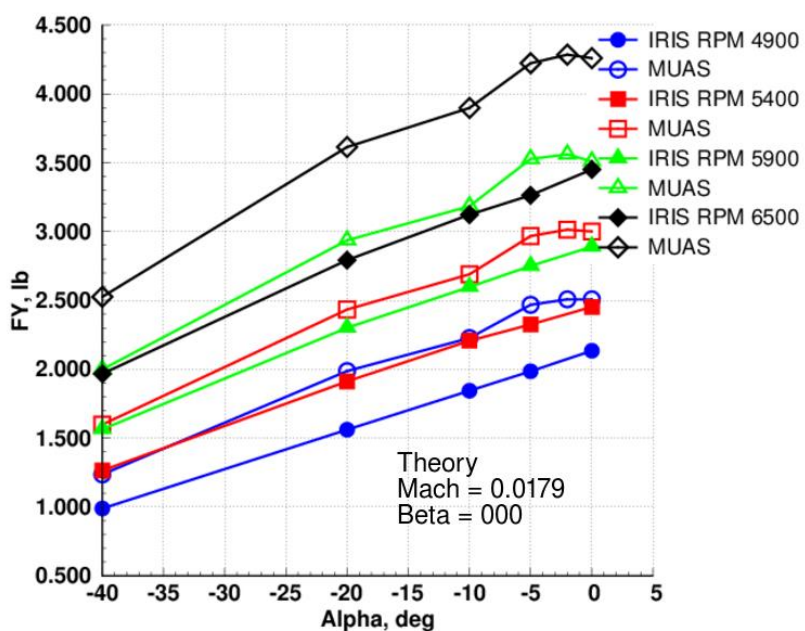

(b)

Figure 9. Forward flight OVERFLOW theoretical rotor disk model results at Mach 0.0179 (a) FX vs. $\alpha$, (b) FY vs. $\alpha$. 
To better simulate the rotor characteristics using the rotor disk model, the SUI074 airfoil data tables were introduced to provide realistic blade airfoil sectional aerodynamics into the rotor model simulation. Shown in Fig. 10 are the OVERFLOW results using the rotor disk model with the SUI074 airfoil table data representation of the rotor aerodynamics and the measured MUAS data. These results represent the forward flight conditions illustrated in Fig. 5b, 5c.

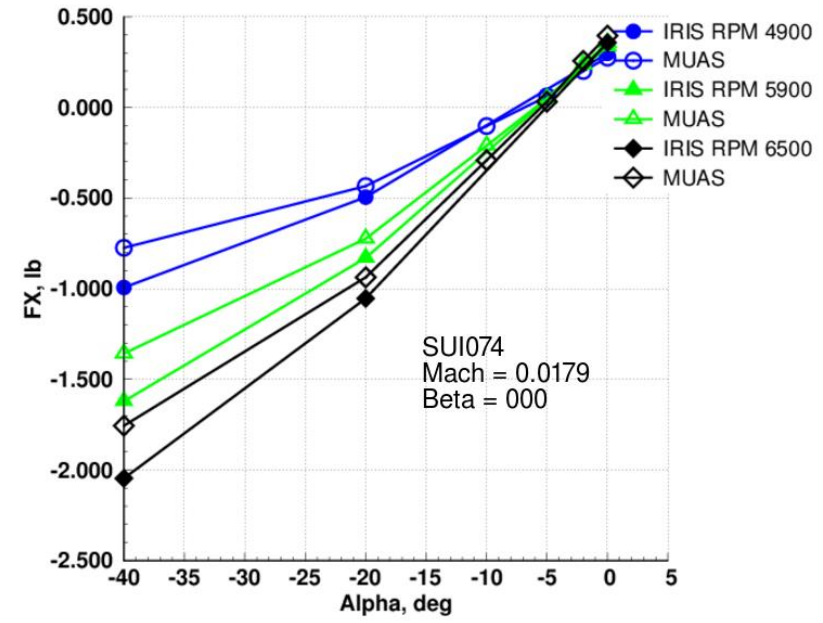

(a)

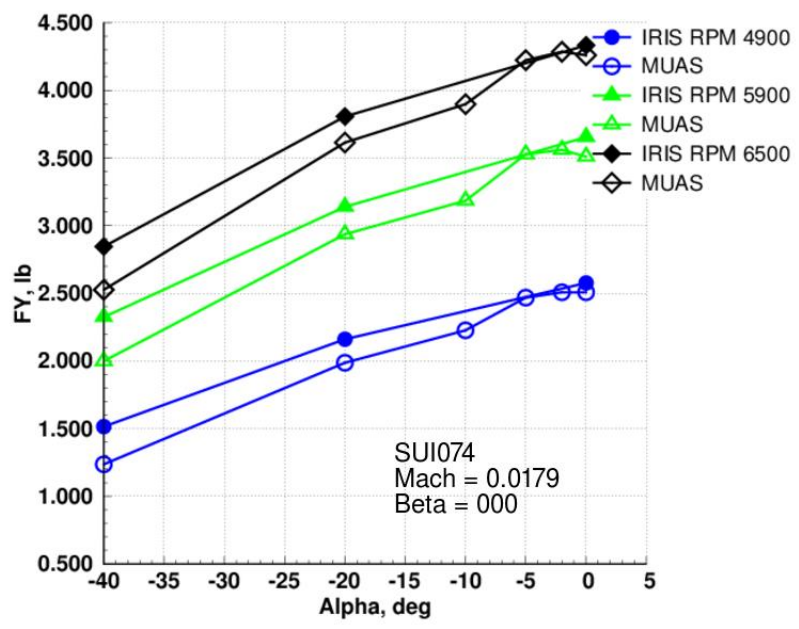

(b)

Figure 10. Forward flight OVERFLOW SUI074 airfoil table rotor disk model results at Mach 0.0179, (a) FX vs. $\alpha$, (b) FY vs. $\alpha$.

The trends in the predicted data, Fig 10, show a marked improvement in agreement with the measured values when compared to the theoretical model results in Fig 9. Note that the values of FX and FY in Figs 9-10 are in dimensional lbf.

OVERFLOW results for the IRIS drone in the NASA-Ames $7 \times 10 \mathrm{ft}$. wind tunnel at Mach 0.0 for varying rotor rpm are shown in Fig. 11 for FX and FM, respectively. These results represent the hover condition with the model oriented normal to the tunnel centerline, see Fig. 5a. Shown in Fig. 11 are the predicted results for the theoretical representation of the rotor aerodynamics, the results for the XV15 and SUI074 airfoil tables, and the measured MUAS data. The trend in the predicted data for the theoretical rotor representation is consistent in trend with the measured values, but there is an offset in FX and FM. This is also observed for the rotor representation using the XV15 airfoil tables. However, when the rotor characteristics are modeled with the SUI074 airfoil tables, an excellent agreement with the measured values is shown for both FX and FM, Fig. 11a and Fig. 11b, respectively. This is attributed to the fact that the SUI074 airfoil data is more representative of the IRIS rotor blade aerodynamics as compared to the theoretical values or the XV15 airfoil data. The SUI074 results for the hover condition, Fig 11, are in better overall agreement with the experimental data as compared to the forward flight results, Figs. 9-10. 


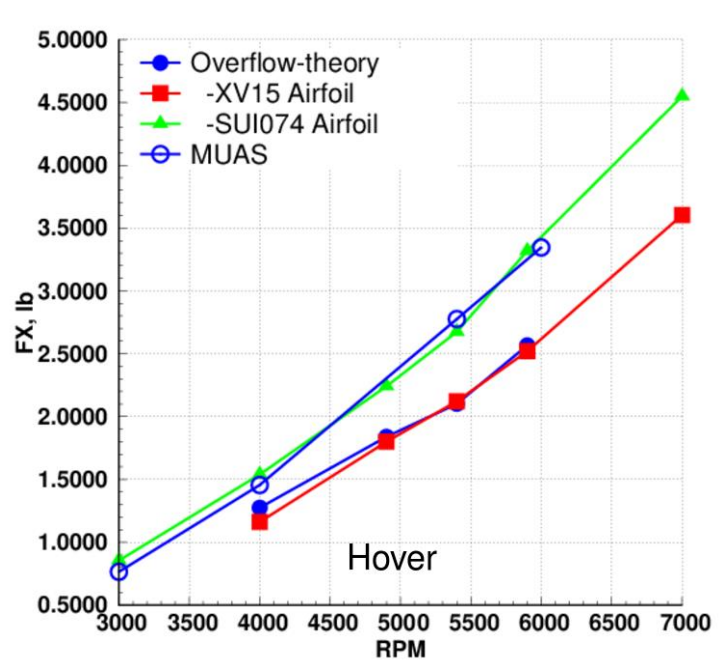

(a)

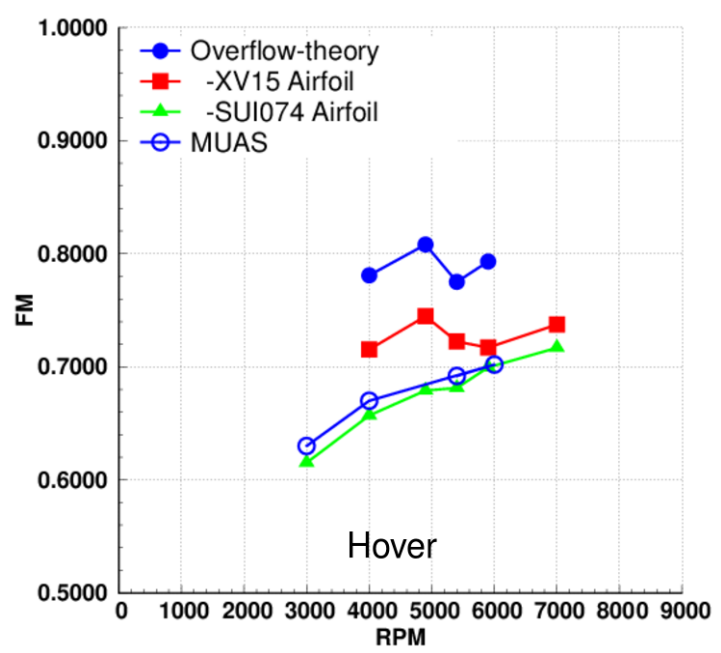

(b)

\section{Figure 11. Hover OVERFLOW theoretical and airfoil table rotor disk model results}

\section{(a) FX vs. rpm, (b) FM vs. rpm.}

Flow field contours for the y-component of velocity and surface pressure coefficient $(\mathrm{Cp})$ on the model at an instance in time are shown in Fig. 12 for Mach 0.0179, rotor rpm 6500, and $\alpha=-10^{\circ},-40^{\circ}$. The contours in Fig. 12a depict the strong interaction of the forward rotor wake flow with the drone body and aft rotor flow at the lower angle of attack, while Fig. 12b indicates a diminished interaction at the higher angle of attack.

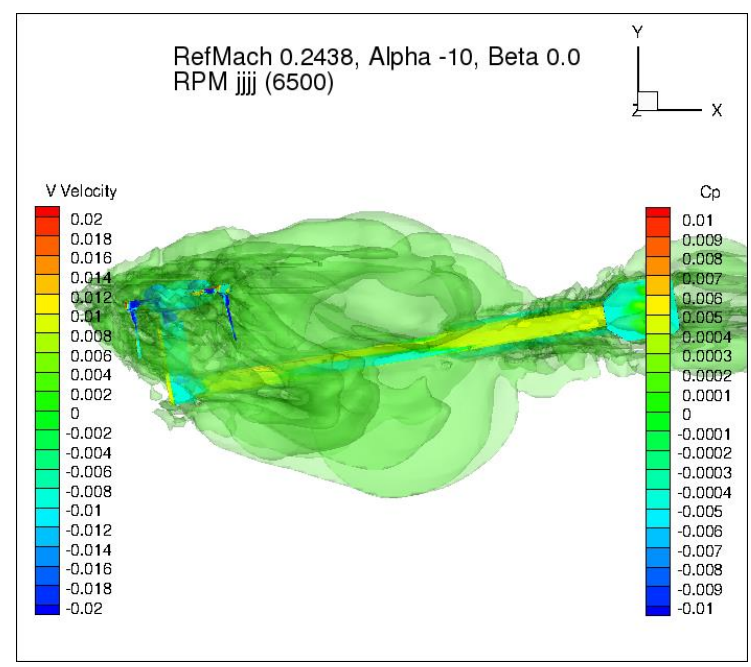

(a)

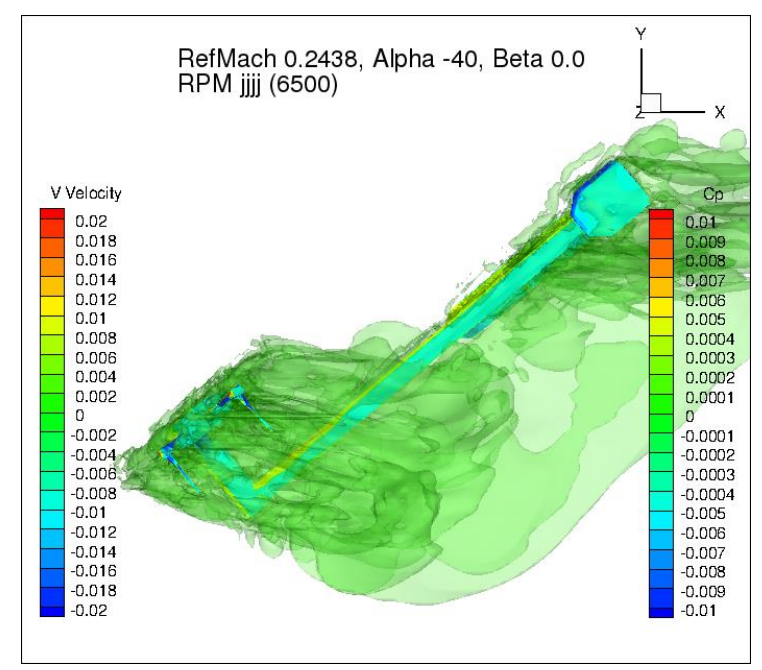

(b)

Figure 12. OVERFLOW results, flow field y-velocity and model surface $\mathrm{Cp}$, rotor disk model, Mach = 0.0179, rotor rpm 6500, and (a) $\alpha=-10^{\circ}$, (b) $\alpha=-40^{\circ}$.

Flow field contours for the swirl and surface $\mathrm{Cp}$ on the model are shown in Fig. 13 for hover, $\alpha=-90^{\circ}$, rotor rpm 4000 and 5900. These contours depict the hover flow field with the rotor wake convected downstream in the tunnel. 


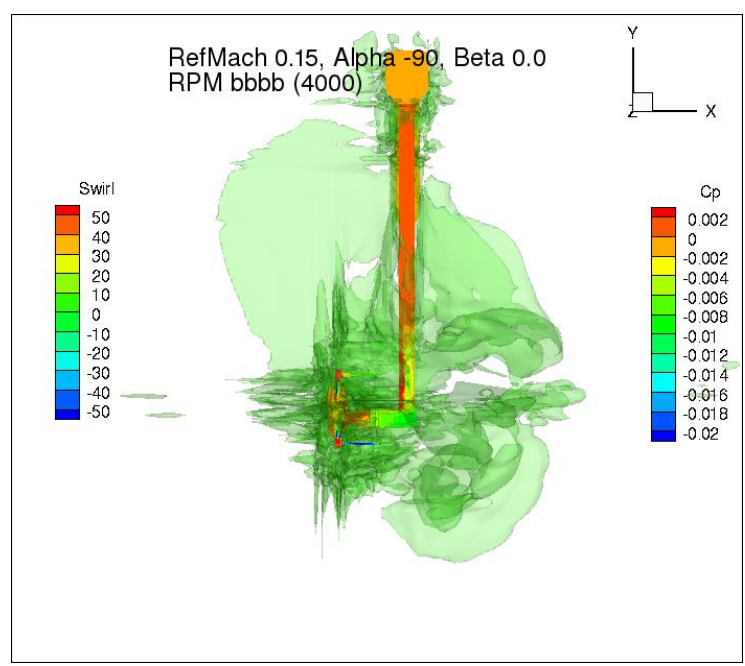

(a)

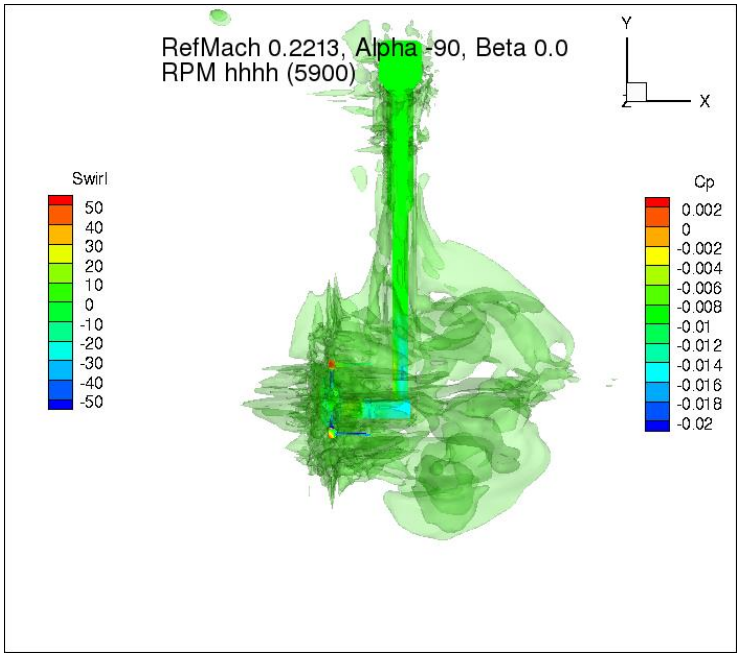

(b)

Figure 13. OVERFLOW results, flow field swirl and model surface $\mathrm{Cp}$, rotor disk model, $\mathrm{Mach}=0.0, \alpha=$ $\mathbf{9 0}^{\circ}$, and (a) rotor $\mathbf{r p m}=\mathbf{4 0 0 0}$, (b) rotor $\mathrm{rpm}=5900$.

\section{B. Individual Blade Simulation Results}

OVERFLOW results for the IRIS drone in the NASA-Ames 7x10 ft. wind tunnel at Mach 0.0179 for varying angle of attack based on including the individual blade solutions are shown in Fig. 14a and 14b for the FX and FY forces, respectively. These results represent the forward flight condition, Fig. 5b,5c. Shown in Fig. 14 are the predicted results for the rotor disk model using the SUI074 airfoil tables, the results for the individual blades solutions, and the MUAS data. Inclusion of the individual blade solutions (IB in the figure legend) are a better match to the MUAS data. This is especially true when the rotor disk is at a greater angle to the free stream flow, $\alpha=$ $-20^{\circ},-40^{\circ}$.

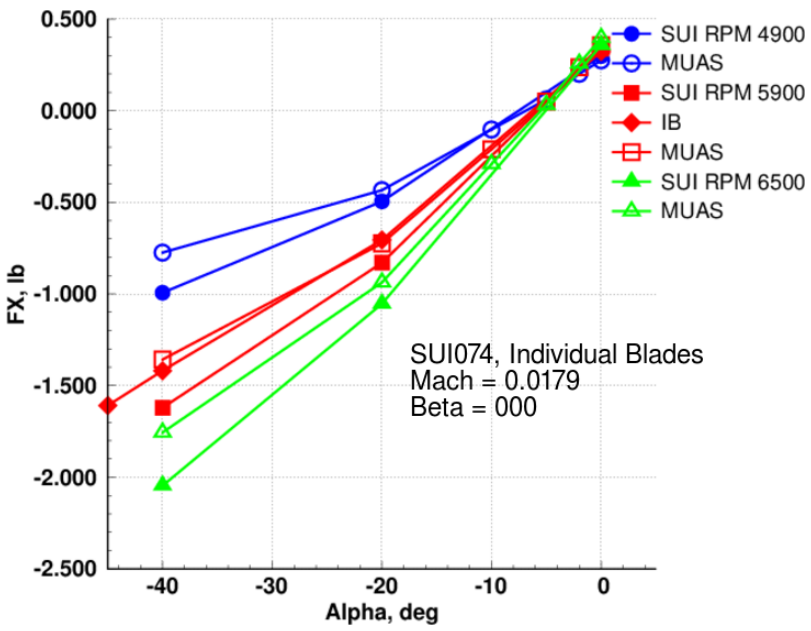

(a)

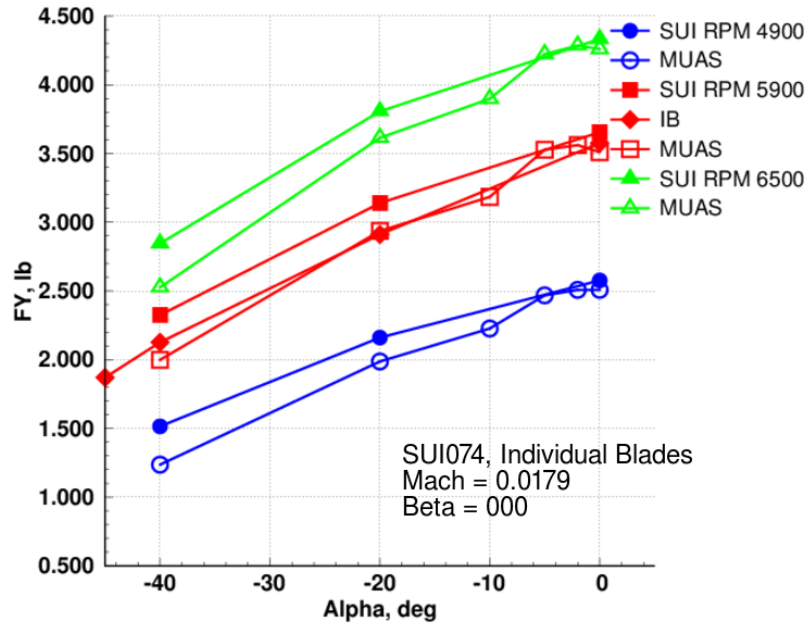

(b) 
Figure 14. OVERFLOW, individual blade vs. SUI074 table results, Mach 0.0179 (a) FX vs. $\alpha$, (b) FY vs. $\alpha$.

Flow field contours from the IB model showing vorticity magnitude and surface Cp on the IRIS with various blade positions are shown in Fig. 15 for Mach 0.0179 and $\alpha=-20^{\circ}$, viewed from the $+Y$ axis. At this angle of attack, the rotor wake persists near the rotor disk with the forward rotor wakes being ingested into the flow of the aft rotors. This is shown in the figure as the large wake aft of the drone and adjacent to the drone between the forward and aft rotors.

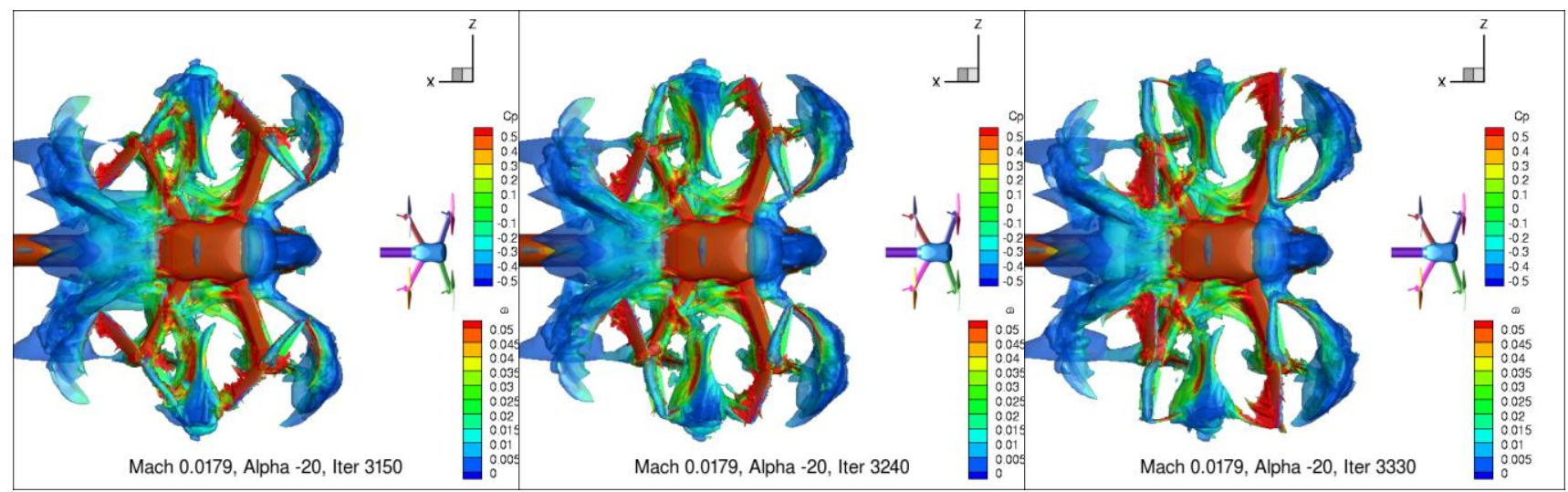

(a)

(b)

(c)

Figure 15. OVERFLOW individual blades flow field vorticity and model surface Cp results at Mach $=0.0179$, $\alpha=-20^{\circ}$, and rotor rotations of (a) $675.0^{\circ}$, (b) $697.5^{\circ}$, (c) $720.0^{\circ}$. Top views from $+Y$ axis with flow from right to left.

Flow field contours for the vorticity magnitude and surface $\mathrm{Cp}$ on the model are shown in Fig. 16 for Mach 0.0179 and $\alpha=-20^{\circ}$, viewed from the $+\mathrm{Z}$ axis. These results show the interaction of the forward rotor wakes with the aft rotor flow and the drone flow field.

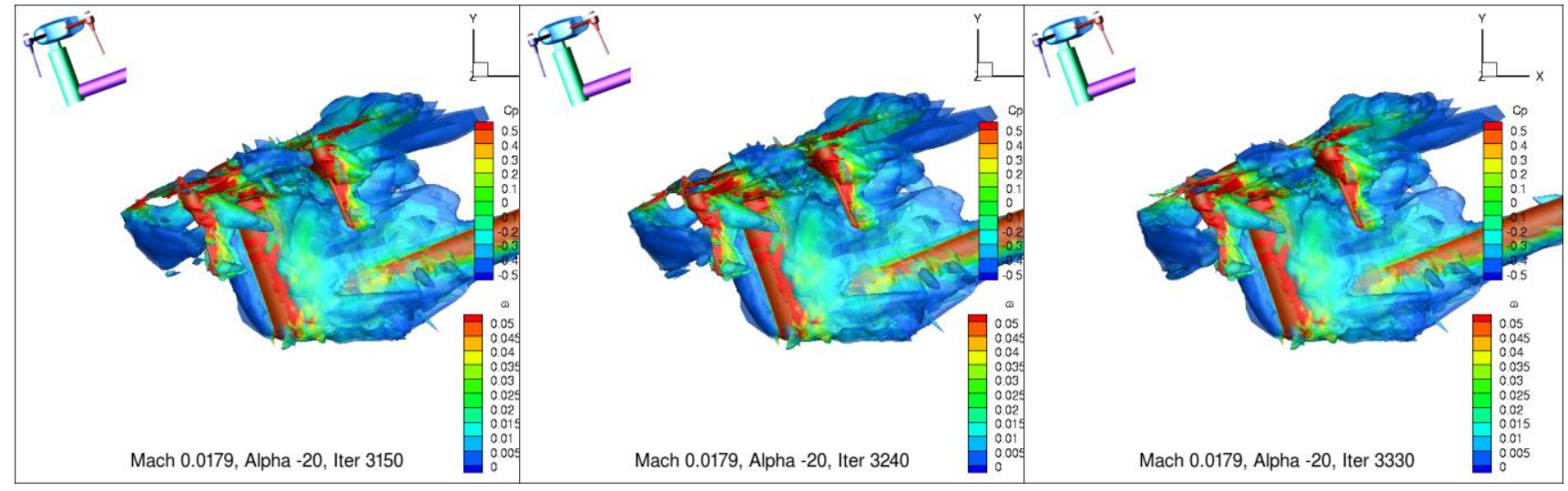

(a)

(b)

(c)

Figure 16. OVERFLOW individual blades flow field vorticity and model surface $\mathrm{Cp}$ results at $\mathrm{Mach}=\mathbf{0 . 0 1 7 9}$, $\alpha=-20^{\circ}$, and rotor rotations of (a) $675.0^{\circ}$, (b) $697.5^{\circ}$, (c) $720.0^{\circ}$. Side views from $+Z$ axis with flow from left to right. 
Flow field contours for the vorticity magnitude and surface $\mathrm{Cp}$ on the model are shown in Fig. 17 for Mach 0.0179 and $\alpha=-40^{\circ}$, viewed from the $+Y$ axis. Unlike the flow at the lower angle of attack, Fig. 15, these results show less forward rotor wake interaction with the aft rotor wakes and drone flow field. At this angle of attack, the forward rotor wake is being transported away from the rotor disk plane.

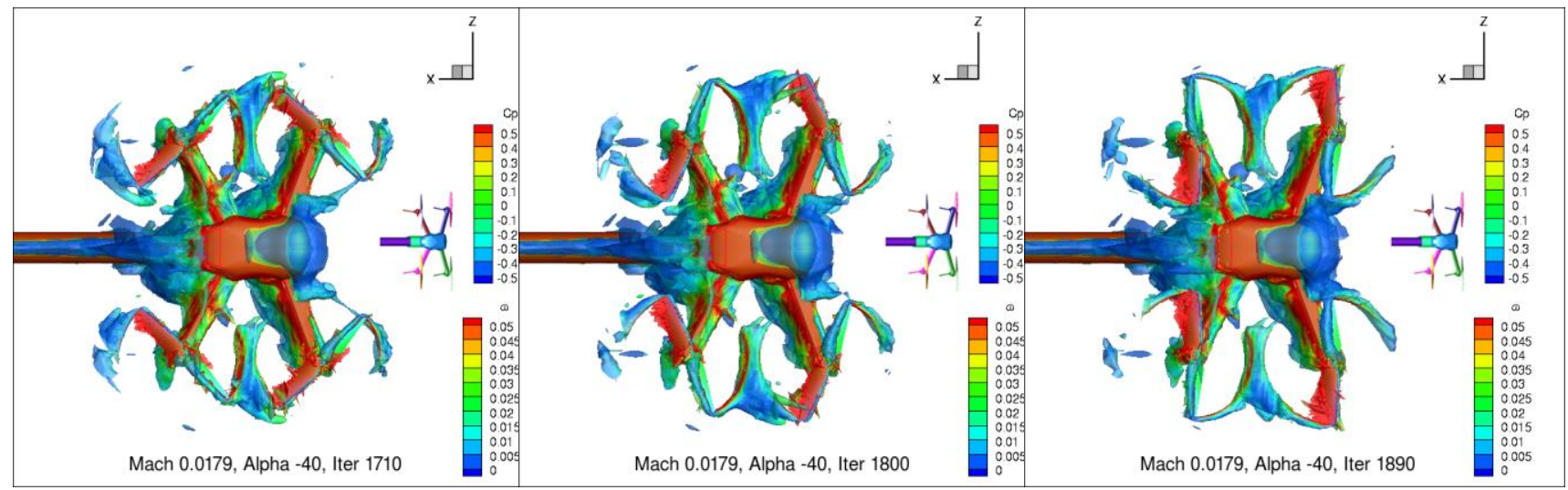

(a)

(b)

(c)

Figure 17. OVERFLOW individual blades flow field vorticity and model surface $\mathrm{Cp}$ results at $\mathrm{Mach}=\mathbf{0 . 0 1 7 9}$, $\alpha=-40^{\circ}$, for rotor rotations of (a) $315.0^{\circ}$, (b) $337.5^{\circ}$, (c) $360.0^{\circ}$. View from $+Y$ axis and flow from right to left.

Flow field contours for the vorticity magnitude and surface $\mathrm{Cp}$ on the model are shown in Fig. 18 for Mach $0.0179, \alpha=-40^{\circ}$, while viewed from the $+\mathrm{Z}$ axis. These results show the increased transport of the forward rotor wakes away from the rotor plane and away from the aft rotors as compared to the lower angle of attack shown in Fig. 16.

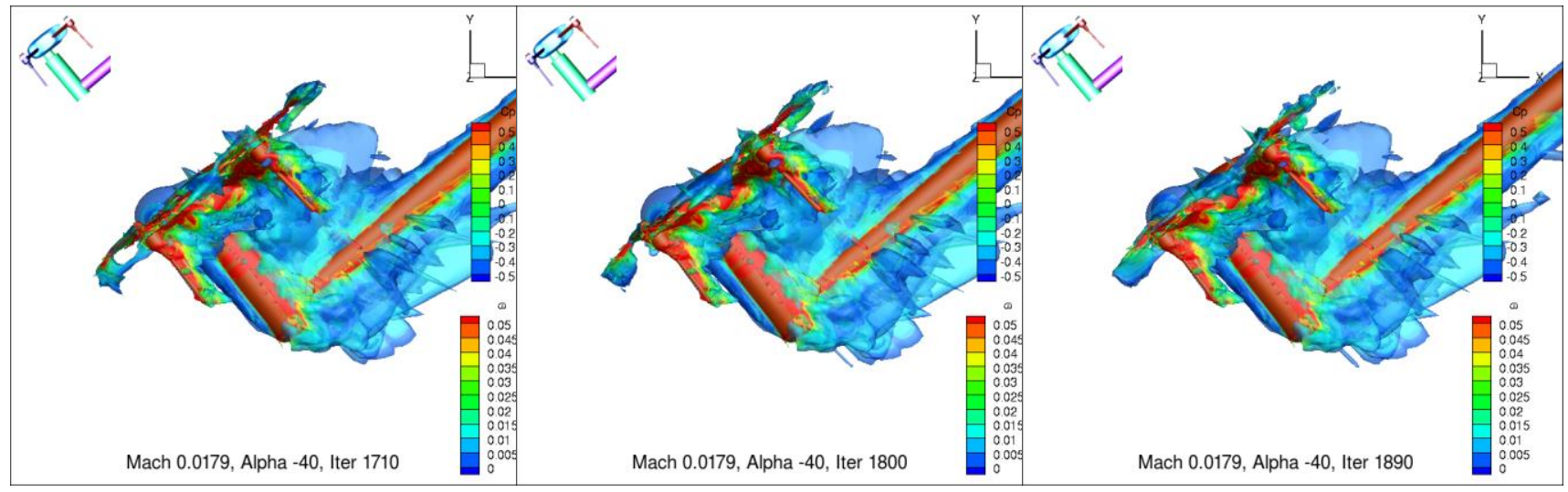

(a) (b)

Figure 18. OVERFLOW individual blades flow field vorticity and model surface Cp results at Mach $=0.0179, \alpha$ $=-40^{\circ}$, with rotor rotations of (a) $315.0^{\circ}$, (b) $337.5^{\circ}$, (c) $360.0^{\circ}$. Side view from $+Z$ axis with flow from left to right. 


\section{Conclusion}

The flow about a small 3DRobotics IRIS quadcopter has been modeled with OVERFLOW using two different rotor models. This study was conducted to provide a simulation process to support NASA's unmanned aircraft system traffic management (UTM) program. In this study, the IRIS drone was modeled as installed in the NASAAmes $7 \times 10 \mathrm{ft}$. wind tunnel. Results were calculated for a range of angles of attack from $-40^{\circ}$ to $0^{\circ}$, for a wind tunnel Mach number of 0.0179 , and several rotor speed values. The model was also simulated in hover for a wind tunnel Mach number of 0.0. These conditions were chosen to provide a direct comparison with available wind tunnel data [2]. OVERFLOW simulations were conducted using the rotor disk model as well as full unsteady inclusion of individual rotating blades. The rotor disk model utilized the theoretical airfoil section definitions of the model and two different airfoil tables defining sectional aerodynamics. Comparisons with the experimental data were conducted. The comparisons demonstrated the ability of the simulation to predict the flow field surrounding the IRIS drone within the NASA-Ames $7 \times 10 \mathrm{ft}$. wind tunnel. The theoretical rotor disk model simulations did not match well with the experimental results. However, when airfoil tables consistent with a drone rotor blade section were included in the rotor disk model, the agreement between the computed and measured results was much improved. This improvement was shown for both qualitative trends and quantitative data levels. The individual rotating blade simulations demonstrated a further improvement in the comparison with the measured data. Flow field simulation contours with the inclusion of individual rotating rotor blades demonstrate the developing flow at two angles of attack. At the lower angle of attack the forward rotor wakes interact with the drone and aft rotor flow

fields resulting in a complex flow in the rotor disk plane. At the higher angle of attack, the rotor wake is convected below the rotor disk plane, as expected, resulting in the signature flow field for rotor simulations.

\section{References}

[1] R.H. Nichols, R.W. Tramel, and P.G. Buning, "Solver and Turbulence Model Upgrades to OVERFLOW 2 for Unsteady and High-Speed Applications," AIAA-2006-2824, AIAA 36th Fluid Dynamics Conference, San Francisco, CA, June 2006.

[2] Russell, C. R., Jung, J., Willink, G. C., and Glasner, B., "Wind Tunnel and Hover Performance Test Results for Multicopter UAS Vehicles," AHS 72 ${ }^{\text {nd }}$ Annual Forum, West Palm Beach, FL, May 16-19, 2016.

[3] Chaffin, M. S., and Berry, J. D., Helicopter Fuselage Aerodynamics Under a Rotor by Navier-Stokes Simulation, Journal of the American Helicopter Society, 42 (3), 1997, pp. 235-243.

[4] Meakin, R.L., "Object X-Rays for Cutting Holes in Composite Overset Structured Meshes,” AIAA-2001-2537, June 2001. 